\title{
EVALUATING THE SECOND WORKSHOP TO BUILD A SAUDI ARABIA- UNITED STATES PARTNERSHIP PROGRAM
}

\author{
Dr. Fatemah Abdullah Alhazmi \\ Taibah University, SAUDI ARABIA, alhazmi07@hotmail.com
}

\begin{abstract}
Taibah University (TaibahU) in the Kingdom of Saudi Arabia (KSA) signed a partnership agreement in April 2015 with George Washington University (GWU) in the United States (US) to develop a Doctor of Philosophy $(\mathrm{PhD})$ program in Educational Administration Leadership. The agreement stipulated that the first workshop would be held in KSA, which subsequently took place in December 2015. This article focuses on the structure and outcomes of the second workshop, which took place between 24 October and 03 November 2016. The workshop revealed that many of the goals of the partnership agreement established in the first workshop had been achieved. In addition, the team discussed the differences between KSA and USA students, in particular in relation to firstly, language and culture, secondly, approaches to public K-12 and higher education and thirdly, methods of identifying and overcoming any barriers resulting from these differences. In addition, there was a discussion of the potential challenges in introducing blended learning, using Blackboard and synchronous online teaching and the type of support required by students in this environment. There was also a consideration of instructor evaluation and ensuring high-quality research from students in both countries. These discussions, along with a number of site visits, led to the drawing up of plans to overcome the issues identified, as outlined in the current article.
\end{abstract}

Keywords: Cultural differences in education, blended learning, international education partnership, educational administration leadership, education in the Kingdom of Saudi Arabia

\section{INTRODUCTION}

The government of the Custodian of the Two Holy Mosques has attached considerable importance to the development of resources necessary to meet the needs of all sectors. This has been undertaken by means of the new Vision 2030, which aims to reduce the current dependence on oil and develop the economy by improving other important sectors, i.e. education, health, tourism and entertainment.

The country (may Allah preserve it) has made strenuous efforts to improve the education sector at all levels, expanding its global educational partnerships over the previous twenty years. Furthermore, Saudi universities have created many international partnerships with the universities of other countries, thus benefiting from programs in various fields. This has led to an increase in new knowledge, different global cultures, and awareness of advanced modern systems.

The General Department of Planning and Statistics of the Ministry of Education (GDPSME, 2010) has indicated its support for a number of contracts and partnership agreements aimed at strengthening these global partnerships and has therefore concluded an agreement with George Washington University (GWU) to create high-quality graduate programs and develop a Doctor of Philosophy (PhD), in order to enhance the leadership of educational administration. The service agreement was implemented in Riyadh as part of the Fifth International Exhibition and Conference on Higher Education (held between 15 and 18 April 2015), which included the partnership between the universities of Thebes (TaibahU) in Madinah and GWU. This aimed to design a doctorate program in educational administration leadership to obtain post-Master degrees for students of TaibahU in Medina. The program was designed by a joint team composed of college 
members from the Graduate School of Education and Human Development (GSEHD) of the Department of GWU and the Department of Educational Administration in Thebes UU, College of Education. It was agreed GWU would award a Post-Master's degree (PMC) as the first part of the program (i.e. eighteen credit hours) through the integrated learning system, while TaibahU would implement the remainder of the $\mathrm{PhD}$ qualification.

\section{Taibah University's vision}

The university's vision focuses on developing inputs and outputs. This includes following up on partnership agreements in order to achieve its goals and orientation and in particular the development of high-quality academic graduate programs. TaibahU has therefore established an agency for postgraduate studies and research, with the primary purpose of enhancing knowledge, cultural and scientific cooperation between members of the TaibahU community and their counterparts working in local and international scientific institutions. This agency aims to establish both local and international cooperation, in order to build bridges between departments and bodies throughout KSA and the rest of the world.

\section{Taibah University}

TaibaU was established in Medina Munawarah in KSA in 2003 AD, as a result of Royal Decree No. 22042, stipulating the decision of the Higher Education Council to merge the campus of Muhammad bin Saud University and King Abdulaziz University into one independent university in Medina. TaibaU is made up of twenty-eight colleges, and the number of students (both male and female) has continued to expand, with a total of 20,815 recorded in 2017.

TaibahU now runs 156 academic programs, of which ninety-four are postgraduate studies, with the resulting qualifications being as follows:

1- Diploma

2- Associate

3- Bachelor degree

4- General diploma

5- Higher diploma

6- Master

7- PhD

Taibah U's mission

To provide high-quality academic programs in various fields.

To develop and support research, including contributing to development and the enrichment of knowledge.

To meet the needs of national development and the requirements of the labor market, in order to produce graduates capable of competing in the knowledge economy in light of globalization.

To promote the role of community service and building a knowledge society.

To provide an on-campus environment supporting productivity and excellence.

The Department of Educational Administration

The TaibaU department of Educational Administration is located within the College of Education (DEA) and includes a number of graduate programs preparing specialists in: (1) educational administration; (2) leadership; (3) planning; and (4) the economics of education. The department also provides training courses for school administrators (school leaders) in association with the Ministry of Education. The high levels of cooperation between faculty members focus on securing excellence and enriching knowledge and practice.

George Washington University (GWU)

GWU is a non-profit organization located in the District of Columbia, USA. The participants in the program under discussion in this paper were chosen from within the university's College of Education, which constitutes the largest higher educational institution in the nation's capital. GWU annually enrolls a diverse group of undergraduates, alumni and professional students from fifty states, as well as the District of Columbia and over twenty countries, and offers degree courses including MA, EdS, PhD and EdD.

This current research analyzes the inputs and outputs of the second workshop, which formed an initial stage 
of the contract between GWU and TaibahU. The aim was to create a doctoral program in Educational Leadership (EL), in light of experience of the visit to GWU. Furthermore, the narration study includes an examination of the ways in which individuals experience the world.

Narrative research is comprised of a number of procedures, including: (1) the collection of data by means of individual stories; (2) the communication of such experiences; and (3) arranging their meaning in a timebased manner. This current study employs a personal approach to collecting deliberations arising from each event, particularly as the researcher played a major role in undertaking the qualitative research methodology, being the primary collector of data. Researchers collect data by reviewing documents, making behavioral observations and interviewing respondents. The number of participants in qualitative studies generally tends to be lower than in quantitative studies, due to qualitative research focusing on a specific set of results, rather than the ability to generalize (Richie, Lewis, and Elam, 2003). It should be noted that the current researcher made use of continuous observation and unstructured interviews for this study.

\section{RESULTS AND DISCUSSION}

The second workshop was held in GWU in the USA between 24 October and 03 November 2016. The objectives were as follows:

- To ensure the joint teams cooperated to review the description of the Post-Master Certificate Program and the Doctoral Certificate curriculum.

- To inform the TaibahU faculty of the educational methods of GWU, in order to assist TaibahU in implementing its own program.

- To define the approach of GWU's Administration of Academic Programs, from student admission requirements to registering students for courses and negotiating research topics with instructors.

- To identify GWU's student educational facilities and services (i.e. library, IT and telecommunications).

- To define the relevant rights and responsibilities of GWU students, along with school policies and requirements.

- To review educational and leadership as taught in American public schools, in order to facilitate a comparison with the program content of schools in KSA.

- To provide a detailed plan of the implementation of programs, including identifying potential challenges and mitigation strategies.

- To identify the skills and experience of the GWU's Education School, in order to facilitate future cooperation in academic research and publishing.

- To promote respectful relationships and friendships between the two faculties, so as to firstly, facilitate communication and secondly, enable the resolving of any challenges potentially arising during the implementation of the project.

\section{Table 1: Second Workshop Activities}

Detailed agenda of the Twelve-day Second Workshop in GWU.

\begin{tabular}{|l|l|l|c|}
\hline & Time & \multicolumn{1}{c|}{ Activity } & Participants \\
\hline Day 1 & \multicolumn{1}{|c|}{$\begin{array}{l}\text { Arrival of the TaibahU Team from Al-Madinah Al- } \\
\text { Munawwarah at Washington DC }\end{array}$} & Taibah U Team \\
\hline $10: 00-1: 00$ & $\begin{array}{l}\text { Introductory meeting and discussion between the GSEHD } \\
\text { leadership and faculties of TaibahU and GWU. } \\
\text { Topics included: (1) general characteristics of students } \\
\text { attending the two schools: (2) curriculum development; (3) } \\
\text { delivery methods; and (4) differences between the two } \\
\text { educational systems. This determined that the success of } \\
\text { this project would require cooperation, patience and } \\
\text { flexibility both within and between the two faculty and }\end{array}$ & \\
\hline
\end{tabular}




\begin{tabular}{|c|c|c|c|}
\hline \multirow[t]{4}{*}{ Day 2} & & $\begin{array}{l}\text { leadership teams. TaibahU's Dean of the College of } \\
\text { Education, U, Dr N, indicated that the program is unique in } \\
\text { its development, due to the support given by KSA's Ministry } \\
\text { of Education. A further professor shared information } \\
\text { concerning cultural challenges identified when creating a } \\
\text { partnership with a university in Pakistan. }\end{array}$ & $\begin{array}{l}\text { TaibahU and } \\
\text { GWU Teams }\end{array}$ \\
\hline & $2: 00-3: 00$ & $\begin{array}{l}\text { The two teams met to discuss the objectives of the } \\
\text { workshop and prepare the agenda. }\end{array}$ & $\begin{array}{l}\text { TaibahU and } \\
\text { GWU Teams }\end{array}$ \\
\hline & $3: 00-4: 00$ & & $\begin{array}{l}\text { TaibahU and } \\
\text { GWU Teams }\end{array}$ \\
\hline & $5: 00-6: 30$ & $\begin{array}{l}\text { The Dean hosted a dinner, over which a discussion took } \\
\text { place concerning the cultural differences between the two } \\
\text { countries, i.e. food, drink, dress, hosting and social } \\
\text { traditions. }\end{array}$ & $\begin{array}{l}\text { TaibahU and } \\
\text { GWU Teams }\end{array}$ \\
\hline \multirow[t]{4}{*}{ Day 3} & $10: 00-12: 30$ & $\begin{array}{l}\text { The teams visited Patriot High School, including a meeting } \\
\text { with the Principal, who delivered a detailed presentation } \\
\text { concerning the school. } \\
\text { Two students gave a presentation on school activities and } \\
\text { student leadership roles. } \\
\text { The teams toured the school, visiting a number of classes, } \\
\text { and being given information concerning curriculum } \\
\text { development for the teaching of History, Spanish, the arts } \\
\text { and Mathematics. }\end{array}$ & $\begin{array}{l}\text { GWU Team and } \\
\text { TaibahU Team }\end{array}$ \\
\hline & $9: 20-1: 30$ & $\begin{array}{l}\text { The team visited Capitol Hill in Washington, which included } \\
\text { a film outlining the development of the US. } \\
\text { This was followed by a tour the Houses of the Congress } \\
\text { and the Senate, with guides introducing various historical } \\
\text { monuments and famous historical figures, along with laws } \\
\text { currently in place to ensure justice for citizens. }\end{array}$ & $\begin{array}{l}\text { GWU Team and } \\
\text { TaibahU Team }\end{array}$ \\
\hline & $2: 00-1: 30$ & $\begin{array}{l}\text { The team toured the facilities of GWU's Gelman Library. } \\
\text { This was followed by a meeting with the Dean of Libraries } \\
\text { and Academic Affairs, who outlined a number of student } \\
\text { services, including guidance on academic writing and } \\
\text { statistical analysis and information services. }\end{array}$ & $\begin{array}{l}\text { GWU Team and } \\
\text { Taibah U Team }\end{array}$ \\
\hline & $5: 00-7: 00$ & $\begin{array}{l}\text { The team attended a lecture on developing a quantitative } \\
\text { research PHD curriculum in advanced statistics. This } \\
\text { included a discussion of methods of balancing different }\end{array}$ & \\
\hline
\end{tabular}




\begin{tabular}{|c|c|c|c|}
\hline \multirow[t]{2}{*}{ Day 4} & & $\begin{array}{l}\text { statistical, mathematical and technical approaches with } \\
\text { those of applied education. }\end{array}$ & $\begin{array}{l}\text { GWU Team and } \\
\text { TaibahU Team }\end{array}$ \\
\hline & 7:10-8:30 & $\begin{array}{l}\text { The team attended a lecture on qualitative research } \\
\text { methods for PhDs. } \\
\text { The lecturer addressed a number of methods employed for } \\
\text { qualitative research. This was a novel subject, drawn up by } \\
\text { an Arab author and included the students' analysis of } \\
\text { academic research issues, i.e. generalization, objectivity } \\
\text { and quantitative research. }\end{array}$ & TaibahU Team \\
\hline \multirow{3}{*}{ Day 5} & 8:00-4:00 & $\begin{array}{l}\text { The teams were given a tour by students, who described } \\
\text { the school, including its advantages and disadvantages and } \\
\text { their recommendations for improvement. } \\
\text { The teams also attended a selection of classes and } \\
\text { discussed differences between the educational systems of } \\
\text { KSA and the USA, in particular curricula, teaching methods } \\
\text { and the preparation of instructors. }\end{array}$ & $\begin{array}{l}\text { GWU Team and } \\
\text { TaibahU Team }\end{array}$ \\
\hline & $5: 00-7: 00$ & $\begin{array}{l}\text { The teams held a discussion on the sponsorship of fellows } \\
\text { within the faculty and doctoral students of the Hampton } \\
\text { Branch of GSEHD. } \\
\text { In addition, they discussed the first workshop, along with: } \\
\text { (1) a potential future partnership between the universities; } \\
\text { (2) current educational issues in both the USA and KSA; } \\
\text { and (3) the reasons some educational systems can be seen } \\
\text { to have progressed in comparison to other states. }\end{array}$ & $\begin{array}{l}\text { GWU Team and } \\
\text { TaibahU Team }\end{array}$ \\
\hline & 9:00-12:00 & $\begin{array}{l}\text { The teams were given a guided tour of Christopher Newport } \\
\text { University (CNU). This was followed by a discussion of the } \\
\text { teacher preparation program with the Dean of the College } \\
\text { of Education and a female student. This is a unique feature } \\
\text { of CNU, in which student teachers are prepared by means } \\
\text { of an MA in elementary or secondary education, which } \\
\text { takes the form of a one-year program following the } \\
\text { bachelor's degree course. They also discussed the } \\
\text { program's field training procedures and assessment of } \\
\text { students. }\end{array}$ & \\
\hline \multirow[b]{2}{*}{ Day 6} & $12: 30-2: 00$ & $\begin{array}{l}\text { The team visited Page Middle School for a general tour of } \\
\text { the school, along with a discussion of its unique programs } \\
\text { and facilities }\end{array}$ & $\begin{array}{l}\text { GWU Team and } \\
\text { TaibahU Team }\end{array}$ \\
\hline & & & \\
\hline Day 7 & $10: 00$ & Return to Washington, D.C. & Taibah U Team \\
\hline
\end{tabular}




\begin{tabular}{|c|c|c|c|}
\hline Day 8 & $10: 00-4: 00$ & $\begin{array}{l}\text { The teams visited the Mount Vernon Museum located at the } \\
\text { farm and house of George Washington, the first president } \\
\text { of the United States, which also includes a distinguished } \\
\text { US history learning center. }\end{array}$ & $\begin{array}{l}\text { GWU Team and } \\
\text { TaibahU Team }\end{array}$ \\
\hline Day 9 & 10:00-2:00 & $\begin{array}{l}\text { The teams visited the African American Museum, which } \\
\text { describes the history of slavery in the US, as well as } \\
\text { liberation movements led by African politicians and others. }\end{array}$ & $\begin{array}{l}\text { GWU Team and } \\
\text { TaibahU Team }\end{array}$ \\
\hline Day 10 & $10: 00-12: 00$ & $\begin{array}{l}\text { The teams met to discuss details of the program } \\
\text { partnership including: } \\
\text { - The number of credits, noting course timing in the two } \\
\text { countries } \\
\text { - An agreement concerning effective teaching methods. } \\
\text { - The nature and use of field training curricula, with a } \\
\text { particular focus on the student from the curriculum } \\
\text { designer's perspective. }\end{array}$ & $\begin{array}{l}\text { GWU Team and } \\
\text { Taibah U Team }\end{array}$ \\
\hline \multirow[t]{2}{*}{ Day 11} & $10: 00-2: 00$ & $\begin{array}{l}\text { The Dean of the GWU's Graduate School welcomed the } \\
\text { TaibahU Team. This was followed by: } \\
\text { 1. A lecture delivered by the TaibahU Team on the theme of } \\
\text { 'Opening the Door of Excellence - a GWU and TaibahU } \\
\text { Partnership'. } \\
\text { 2. The Dean of the GWU Graduate School gave a number } \\
\text { of souvenirs to the TaibahU Team. } \\
\text { 3. The Dean of TaibahU's College of Education, Dr N, } \\
\text { expressed gratitude and delivered gifts to the GWU } \\
\text { teaching staff for their effort and time during the workshop. }\end{array}$ & $\begin{array}{c}\text { All teaching staff } \\
\text { at GWU GSEHD } \\
\text { and } \\
\text { GWU Team and } \\
\text { TaibahU Team }\end{array}$ \\
\hline & $2: 00-4: 00$ & $\begin{array}{l}\text { The teams attend a training course on the use of } \\
\text { Blackboard, followed by a discussion of the ways this could } \\
\text { serve the partnership agreement between the two } \\
\text { universities, i.e. teaching and communication with students. }\end{array}$ & $\begin{array}{l}\text { GWU Team and } \\
\text { TaibahU Team }\end{array}$ \\
\hline \multirow[t]{2}{*}{ Day 12} & 10:00- 2:00 & $\begin{array}{l}\text { The team attended a lecture on the planning and writing of } \\
\text { theses at GWU, including approaches for improving student } \\
\text { research output. }\end{array}$ & \\
\hline & $2: 30-4: 00$ & $\begin{array}{l}\text { The teams visited the Education Policy Center (CEP). } \\
\text { This included CEP members outlining the nature of their } \\
\text { operation, along with their role in suggesting and presenting } \\
\text { solutions for educational problems to decision-makers. }\end{array}$ & $\begin{array}{l}\text { GWU Team and } \\
\text { TaibahU Team }\end{array}$ \\
\hline
\end{tabular}




\begin{tabular}{|c|c|c|}
\hline $4: 14-6: 00$ & $\begin{array}{l}\text { Team meeting between the two universities. } \\
\text { The teams discussed the output of the second workshop, } \\
\text { along with the necessary further steps for implementing the } \\
\text { agreement and preparing the inauguration of the PhD } \\
\text { program on a timely basis. The points discussed and } \\
\text { agreed upon during this meeting were as follows: } \\
\text { - Reformulating curricula in relation to the changes agreed } \\
\text { between teaching staff at the two universities, including: (1) } \\
\text { details of curricula; (2) distribution of credit weeks; and (3) a } \\
\text { change in some of the proposed policies, to ensure they } \\
\text { were in line with the nature of TaibahU. } \\
\text { - Reviewing academic accreditation criteria and the } \\
\text { requirements to conform to such criteria. } \\
\text { - Additions to the program description, i.e. a thesis writing } \\
\text { guide. } \\
\text { - Drafting a detailed report following the implementation of } \\
\text { the program, in order to identify its strengths and } \\
\text { weaknesses and so ensure future improvement. } \\
\text { - Setting a date for the TaibahU teaching staff to finalize the } \\
\text { translation of curriculum description. } \\
\text { - Developing the program vision and mission. } \\
\text { - Setting accurate criteria for selecting students for } \\
\text { admission to the first class (i.e. Summer } 2017 \text { ). } \\
\text { - Facilitating and finalizing electronic means of } \\
\text { communication at the two universities in Spring } 2017 \text {. } \\
\text { - Finalizing the translation of the complete program into } \\
\text { Arabic, for presentation to the accreditation entity at } \\
\text { TaibahU. } \\
\text { - Finalizing methods of communication with schools and } \\
\text { universities for implementation of field training curricula in } \\
\text { the sphere of public and higher education. } \\
\text { - Establishing cooperation between the TaibahU and GwU } \\
\text { teams to draw up a scientific paper on the partnership } \\
\text { project. } \\
\text { - Introducing a timetable for future meetings of the two } \\
\text { teams, to ensure the progress of the project steps. }\end{array}$ & $\begin{array}{l}\text { GWU Team and } \\
\text { TaibahU Team }\end{array}$ \\
\hline
\end{tabular}

\section{DISCUSSION}

The first meeting consisted of an introduction of the various members of the design team from KSA to the Dean, associate deans, and faculty of GWU. The teams discussed both the challenges and the lessons of the partnership. Members of both teams indicated that the success of the international partnership was due to commitment, passion and flexibility. The dean indicated that the program had attracted the interest of several stakeholders in KSA, including the Ministry of Education. This confirmed that the program was expected to serve as a pilot within TaibahU and other higher learning institutions in KSA.

Discussions concerning the structure of the program using that of a Post Master's Certificate (PMC) (which was not yet in existence in KSA) revealed that the development and implementation of the PMC course was to be initially undertaken by means of the PhD course developed during the implementation of PMC. However, changes were made to this plan, as a result of the requirements of the complete program, which needed to be in place prior to any implementation. Obstacles facing the process included: firstly, the differences between the learning models of TaibahU and GWU and secondly, the need to hold simultaneous classes while taking account of the different time zones of the two countries. The dean also held a discussion 
on the potential for establishing two internships in PMC, which is not a common feature of PhD programs offered in KSA. Such internships were demonstrated as being beneficial in relating theory to practice.

One professor from GWU inquired whether the program was to be curriculum or instruction based, or if it would be focused on institutional leadership. The team clarified that KSA had a national curriculum, with the participants from TaibahU also considering the future plans of prospective students following completion of the new PhD program. This information could therefore prove beneficial to those designing the curriculum, including forming the basis for identifying the most useful materials and skills to be integrated into the course in order to meet those expectations.

The meeting also discussed issues concerning: (1) the commitment of students following graduation; (2) the use of a full-time or part-time mode of study; (2) the willingness of employers to allow their employees to pursue higher education; and (3) government funding of education. The KSA design team indicated that, in following such a course, students would not necessarily return to their previous jobs, and that the government would require them to undertake public service for the number of years equal to that spent in education.

When the team from KSA asked the GWU team to identify the lessons they could offer in relation to international partnerships, GWU responded that they had developed a partnership with a Pakistani institution. Differences between the academic procedures and the cultures of the two countries resulted in this partnership being complex, but both institutions coordinated a number of additional steps to ensure a more effective means of working together.

During a meeting with GWU Vice President for Research, the team discussed potential research generated by the partnership. The dean noted the results of the TIMSS data from the commencement of participation by KSA. The data indicated a need for some improvement among academics in KSA, including that the lesser emphasis on assessment in KSA in comparison to the US suggested difficulties in identifying certain elements of Saudi education.

The team visited three K12 institutions, including: (1) a gifted education center for children aged between three and eight; (2) a comprehensive high school; and (3) a new middle school. These visits to led to a number of discussions concerning K-12 education, encompassing the first levels to matriculation.

The team also visited various learning resource centers, in order to observe both physical and online resources. In addition, members also: (1) underwent training on the Institutional Review Board (IRB) and on Blackboard (Bb); (2) attended GW Educational Leadership student classes; and (3) visited CEP. The IRB training covered the process of submitting research through GWU. The team also visited the writing center to learn how it supported students.

The class visits were fundamental to this process, awarding the team direct knowledge of instructional procedures utilized in courses in research techniques, while the visit to CEP offered an example of an association that had no need of being subsidized by the college or the legislature. The exchange focused on performing research that was impartial or impacted by other advanced education establishments and associations. The KSA faculty learned that that the fact that most of their undergraduate students attend fulltime, along with those attending the master's level college, differs from the USA, where most students tend to work full time while seeking their alumni work.

At this point, the discourse focused on the significant contrast between in the utilization of evaluation for K12 instruction. Educators working in KSA schools are not constantly subject to evaluation, while those in the US frequently feel over-evaluated. Senior member noted their desire to achieve a balanced approach to evaluation. It was noted that $\mathrm{K}-12$ classes in the US tend to be more interactive than those in KSA. A discussion was also held on the issue of global qualifications for educators around the globe, with both members from both countries agreeing that recruitment could be improved in order to determine who can (and should) become an educator.

One meeting was held specifically for course designers and topic specialists (SMEs) from Educational Administration and another for those from Higher Education and Research, in order to strategize the coordination of web-based learning and how this could be completed by the deadline. The discourse additionally incorporated the number of hours required for: (1) individual contact between undergraduates and instructors, and (2) the number of hours per week every teacher would be accessible. Educating by means of synchronized online conditions would be a new experience for the majority of GWU instructors, who were currently either teaching entirely in the classroom or non-concurrently on the web. The courses comprising the PMC were reconsidered to ensure the six classes were completed in two semesters. There was also a discussion of the additional pressure on Saudi undergraduates learning in English, including 
proposals for a number of pre-learning exercises capable of preparing such students for the rigor of these courses.

Towards the end of the visit, the DT from Saudi gave a presentation to the GSEHD team faculty. This was well received and gave an exhaustive review of instruction in KSA and the association with GWU.

\section{OUTPUTS OF THE SECOND WORKSHOP}

On the final day, the team discussed the outputs of the second workshop and identified the steps to be performed by both teams during the following stages in order to prepare for the initiation of the PhD program in a timely manner. This included:

- Reformulating curricula in response to the changes agreed by the teaching staff from the two universities, including the particulars of curricula, distribution of credit weeks, and a change of some proposed policies to ensure they were in line with the nature of TaibahU.

- Reviewing academic accreditation criteria and the requirements for conformity to such criteria.

- Adding to the program description, i.e. a new guide on thesis writing.

- Drafting a detailed report following the implementation of the program, in order to identify its strengths and weaknesses for future improvement.

- Setting a date for the TaibahU teaching staff to finalize the translation of the curriculum description.

- Developing the program vision and mission.

- Setting accurate criteria for selecting a good sample of students for the admission of the first class of summer 2017.

- Facilitating and finalizing electronic means of communication at the two universities in spring 2017.

- Finalizing the translation of the complete program into Arabic, for presentation to the accreditation body at TaibahU.

- Establishing methods of communication with schools and universities for the implementation of field training curricula, in particular in the fields of public and higher education.

- Ensuring cooperation between the teams from TaibahU and GWU to create a scientific paper on the partnership project.

- Introducing a timetable for the next meetings between the two teams, to ensure proper progress of the project steps.

\section{THE FOLLOWING STEPS WERE IDENTIFIED DURING WORKSHOP DISCUSSIONS}

1. Course Design Syllabi work: This established the need to finish and clarify the PMC and PhD courses, requiring GSEHD's DT to send all course-related reports to TaibahU's DT for feedback, including: (1) schedules; (2) course portrayals; (3) proposed perusing materials; and (4) ELCC/CAEP gauges for key evaluations

2. Review of CAEP and NCAAA standards.

3. Admission criteria and program commencement dates: Due to SC commencing during fall 2017 , it was established that the principal PMC undergraduates should be enrolled on the program during summer 2017. DT was required to create the affirmation criteria for selection of qualified contenders for the program. It was emphasized that this work needed to start immediately, in response to the need for confirmation by both colleges.

4. Technology prerequisites for the half-breed display: Although GWU led completely online courses in different controls (incorporating Educational Administration), the cross-breed natures of the PMC program required significant preparation to guarantee effective instructional innovation could be embraced by the two colleges. The rundown of necessities incorporated protecting educators at the two establishments, who were prepared for utilizing Blackboard Collaborate to instruct in the half breed program. It was agreed that this should be completed by the end of spring 2017.

5. Translators: SC stated that TaibahU's DT would distinguish, train, and allocate personnel to translate key course materials from English into Arabic. In addition, the DT of the two colleges would carefully screen and facilitate the interpretation of the course throughout summer 2017. 
6. Internship courses and organizations with schools and advanced education establishments: TaibahU was tasked with creating associations with $\mathrm{K} 12$ schools and advanced education foundations prior to the execution of SC. Undergraduate studies gain the greatest advantage from involvement at entry level, i.e. when participating schools are aware of a program and take an interest in its advancement. It was agreed that TaibahU would share the participating $\mathrm{K}-12$ schools and advanced education establishments with those of GWU's DT during fall 2017. In response, GWU's DT agreed to recognize the schools the TaibahU group would visit during the Summer Institute Program in August 2017.

7. Research Partnerships: It was recognized that SC offers opportunities to set up coordinated research and organization between employees of the two colleges. It was agreed that this would expand on the work commenced by DT through progressive meeting introductions at ISEP gatherings, but that increased involvement would be required to transform the structure and execution into an examination venture. This would require the DT of the two colleges to create a proposal and present an IRB application to start the work. It was noted that one of the most significant factors enabling both staff members and undergraduates to complete their studies related to the completion of research. In addition it was also agreed that DT would examine the potential for subsidizing resources to ensure such research.

8. DT Meetings: It was agreed that the DT of the two colleges would coordinate work calendars and meeting dates, in order to guarantee fulfilling the needs of the relevant regions. In addition, future meeting dates would be finalized at the end of the December meeting.

\section{ASSESSMENT OF PUBLIC AND HIGHER EDUCATION}

Public Education

- The organizational hierarchy of the schools visited covered both academic and administrative aspects, including separate leaders for curricula and aspects related to school buildings. Furthermore, each school employed cooperative consultants to support the different aspects.

- The schools were found to have gone beyond the theoretical aspect to ensure a thorough method of preparing students to engage effectively with the labor market, i.e. training in leadership or introducing subjects of a manual nature during the secondary stage.

- The schools were found to have been provided with all necessary facilities to facilitate an environment designed to motivate students, such as:

- Provision of security and safety.

- The selection of a suitable school location, i.e. the availably of space and the ability to avoid crowded areas.

- Attention to the interior and exterior design of the school and the provision of entertainment in order to benefit the students' performance and encourage them to learn.

- The engagement of all students in school activities, in particular during the middle and secondary stages, and the appointment of student leaders to administer such activities, in order to employ students' energies for the benefit of both themselves and their school during these two sensitive stages.

- High levels of participation among all school members, in particular students and teachers, in implementing the vision and mission of the school.

- The effective use of modern technology in classrooms and all school facilities.

- Attention to subjects related to the arts and their role in encouraging students to appreciate culture and beauty.

- Integration and consistency between all education sectors serving the school, including the participation of parents and the community.

- The use of contemporary methods for teaching different languages to students, so enabling them to expand their intellectual potential by exploring other cultures, i.e. Arabic, Spanish, French and German.

- Establishing communication channels between students by placing signs in the corridors for students to record their interests and hobbies and so establish common interest groups.

- Encouraging students from the beginning of the academic year to prepare projects in all curricula for participation in competitions held at a specific date at the level of all US states. 


\section{HIGHER EDUCATION}

- The committees representing the colleges were not expected to operate in a separate manner from the members, instead periodically attending viewings of detailed slides of their operations chaired by the Dean, followed by a discussion and a vote.

- There was a need to pay additional attention to the applied, as opposed to the theoretical, aspect of postgraduate students.

- There was a need to ensure the provision of complete University Public Library services, including an office for research consultancy to assist students complete their research and avail themselves of graduate experience.

- Some university departments were found to prepare MA students for teaching by means of a thorough instrument role improvement program, i.e. that of Christopher Newport University (CNU).

- There was a need to establish diversified teaching and coping with improvement of postgraduate student skills in qualitative and quantitative scientific research.

- There was a need to initiate discussion and the exchange of ideas among postgraduate students, as well as motivating them to read, apply critical thinking and continuous self-learning.

\section{CONCLUSION}

Following the conclusion of the second workshop, it has been confirmed that the two universities met their targets and held important discussions on subjects related to public and higher education, including: (1) teacher preparation; (2) postgraduate admission policies; (3) postgraduate program management; and (4) linking development initiatives to environmental and state conditions. In addition, they exchanged perspectives relating to general aspects of life (i.e. differences between cultures), as well as visits to public and historical facilities aimed at giving members additional information. This comprehensive view of culture in general, and education in particular, enabled the teams to identify potential difficulties in the implementation of the agreement, including barriers related to: (1) language; (2) culture; (3) methods of effective communication; (4) students' approach to sharing knowledge; and (5) student assessment.

The two teams suggested a number of solutions to avoid potential difficulties facing the progress of the program, including: (1) in order to avoid any potential language barrier, students should be proficient in English and (2) the need to meet students following admission in order to facilitate orientation to the program and to the GWU faculty. The TaibahU Department of Educational Management faculty subsequently planned to ensure effective coordination of this aspect and to ensure students would feel supported. The TaibahU faculty pointed out to the GWU Team the importance of noting cultural and individual differences between the students and effective communication when using Blackboard. Finally, the outcome of research determining whether the partnership can fulfil its objectives was seen to be a critical aspect of the program. Three participating students were found to be among the highest achieving GWU students in 2018.

\section{ACKNOWLEDGEMENTS}

I would not have been able to complete this research without the aid and support of countless individuals. Firstly, I am extremely grateful to my colleagues in TaibahU and GWU, who worked hard to achieve the goals of the partnership undertaken between the two universities. Secondly, I would like to offer my sincerest gratitude to those providing assistance with language and the proof reading of this article, i.e. Elsevier Language Editing Services.

\section{FUNDING SOURCES}

This research did not receive any specific grant, it is self-funding.

\section{REFERENCE LIST}

Clandinin, D. J., \& Connelly, F. M. (1990). Stories of experience and narrative inquiry. Educational Researcher, 19(5), 2-14.

Creswell, J. W. (2012). Educational research: Planning conducting and evaluating quantitative and qualitative research (4th edition). Boston, MA: Pearson. 
Creswell, J. W. (2013). Qualitative inquiry and research design: Choosing among five approaches (2nd ed.). Thousand Oaks, CA: Sage Publications.

GDPSME (2010)

Jie, Y. (2010). International partnerships: A game theory perspective. New Directions for Higher Education, 2010, 43-54. doi:10.1002/he.389.

Lieblich, A., Tuval-Mashiach, R., \& Zilber, T. (1998). Narrative research: Reading analysis, and interpretation. Thousand Oaks, CA: Sage.

Lincoln, Y. S., \& Guba, E. G. (1985). Naturalistic inquiry. Thousand Oaks, CA: Sage Publications.

Merriam, S. B. (2002). Introduction to qualitative research. In S. B. Merriam (Ed.) Qualitative research in practice: Examples for discussion and analysis (pp. 3-17). San Francisco, CA: JosseyBass.

Rashad, M. (2016). Saudis await Prince's vision of future with hope and concern. Reuters. Retrieved from http://www.reuters.com/article/us-saudi-plan-idUSKCNOXLOB2.

Ritchie, J., Lewis, J., and Elam, G. (2003). In Ritchie J., Lewis J. (Eds.), Qualitative research practice: A guide for social science students and researchers. London, California, New Delhi: Sage.

Seidman, I. (2006). Interviewing as qualitative research: A guide for researchers in education and the social sciences (3rd ed.). New York, NY: Teachers Press 